\begin{tabular}{cc}
\hline & \\
&
\end{tabular}

\title{
SYNGAP1 Mutation in absence Epilepsy with eyelid myoclonia: A Literature Overview and A Case Report from Qatar
}

\author{
Rana AL-Shami , Sondos Altaraqji, Khalid Mohamed \\ Pediatric Neurology Sidra Medicine
}

\section{ABSTRACT}

Background: SYNGAP1, which encodes a RAS-GTPase-activating protein, is located on the short arm of chromosome 6.Mutations of the SYNGAP1 gene were first identified in 2009 in patients with nonsyndromic intellectual disability (ID) acquired microcephaly, and autism spectrum disorder (ASD), followed in 2013 by recognition of their important role in the developmental and epileptic encephalopathies (DEEs). Developmental delay was identified soon after birth in the majority of patients and preceded seizure onset in all. Development regressed or plateaued with seizure onset were observed. Language was severely impaired together with intellectual disabilities and some other features $(1,4)$.Most affected individuals have de novo mutations, with truncating mutations predominating, although missense mutations, chromosomal translocations, or microdeletions disrupting SYNGAP1 are also described. $(1,5)$.

Keywords: SYNGAP1, Epilepsy, Pediatric
*Correspondence to Author:

Sondos Altaraqji

Pediatric Neurology Sidra Medicine

How to cite this article:

Rana AL-Shami, Sondos Altaraqji, Khalid Mohamed. SYNGAP1 Mutation in absence Epilepsy with eyelid myoclonia: A Literature Overview and A Case Report from Qatar. International Journal of Case Reports, 2021 5:211.

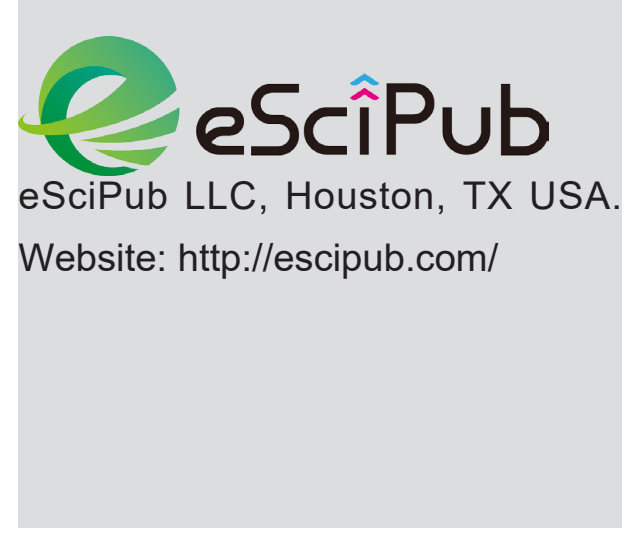




\section{CASE REPORT:}

We report a 9 years old girl with history of developmental delay with heterozygous pathogenic variant in SYNGAP1 gene presented with frequent episodes of vacant look with eye blinking, her EEG reviled Generalized burst of polyspikes and slow wave pattern.

Started on valproic acid and kept on $40 \mathrm{mg} / \mathrm{kg}$ /day .her follow up EEG showed:

Reasonable background, with frequent runs of brief spike and polyspike and wave abnormality

Associated with clinical eye blinking and lip smacking, which occurred in around 5 of the 10 episodes.

Valproic acid started and she had both clinical and electroencephalographic improvement concerning her absence seizures.

\section{DISCUSSION:}

In a cohort study done by Danique et al on 57 patient with SYNGAP1 mutations. Of the 57 patients, 56 had epilepsy: generalized in 55, with focal seizures in 7 and infantile spasms in 1 . Median seizure onset age was 2 years. A novel type of drop attack was identified comprising eyelid myoclonia evolving to a myoclonic-atonic $(n=5)$ or atonic $(n=8)$ seizure. Seizure types included eyelid myoclonia with absences (65\%), myoclonic seizures (34\%), atypical (20\%) and typical (18\%) absences, and atonic seizures (14\%), triggered by eating in $25 \%$.(1).

A distinctive generalized epilepsy phenotype emerged combining features of 2 well-described syndromes, epilepsy with eyelid myoclonia with absences, reported by Jeavons, and epilepsy with myoclonic-atonic seizures, described by Doose et al. other seizure types, including EM, myoclonic, and atonic (and combinations of all 3). TCS were frequent, whereas focal seizures occurred in a minority. $(2,3)$.

About the EEG finding on the same abovementioned study, EEG results were available for 52 of 57 patients from when their epilepsy was active. Many children did not have further EEGs because of severe behavioral problems. GSW and generalized poly-spike wave were reported in 39 of $52(75 \%)$ patients. Focal or multifocal epileptiform discharges were seen in 28 of 52 (54\%), often in addition to GSW or generalized poly-spike wave (21 of $39,54 \%)$. Slow background activity was seen in 26 of 52 (50\%) patients.

Initial EEG :

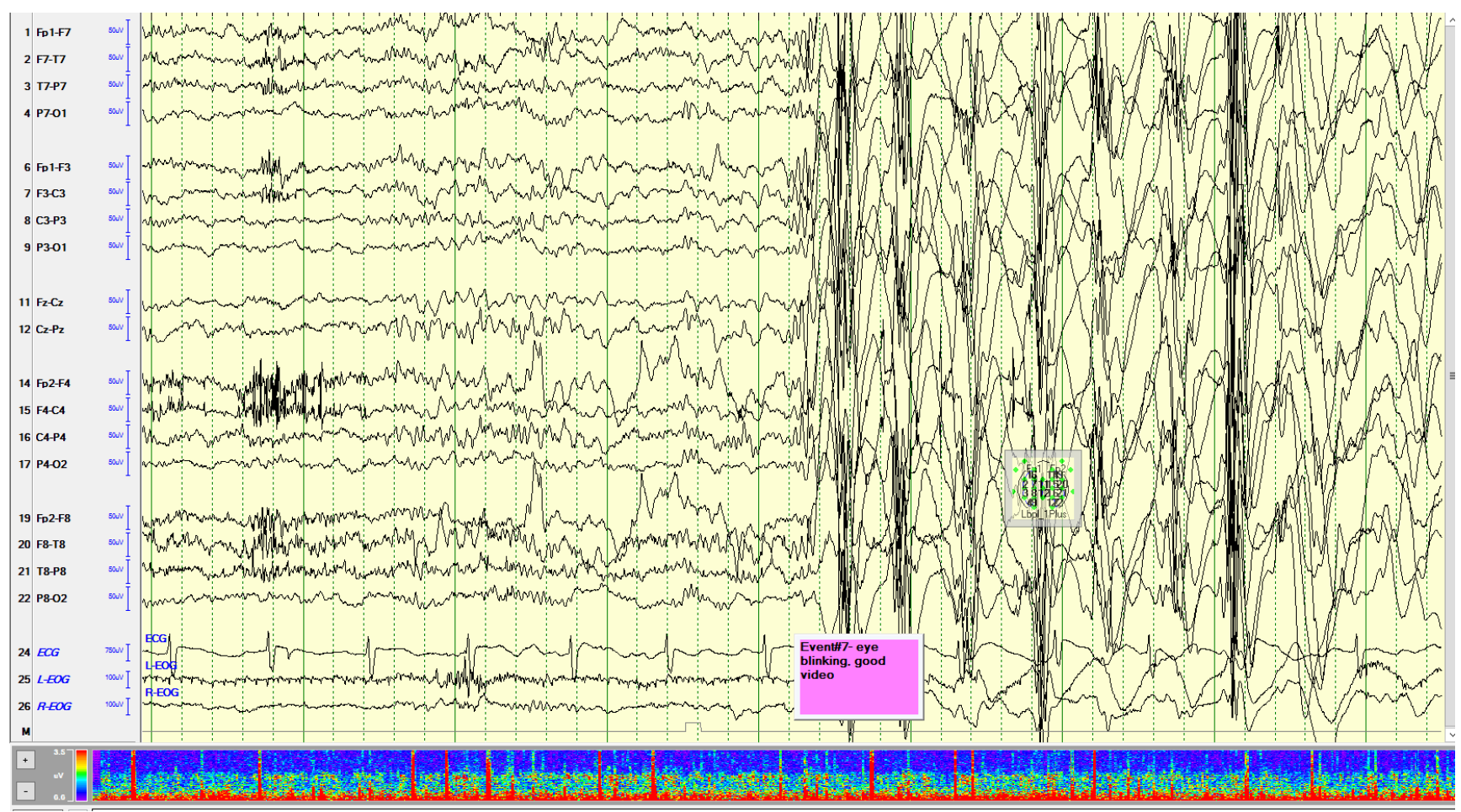

IJCR: https://escipub.com/international-journal-of-case-reports/ 
Follow up EEG as below:

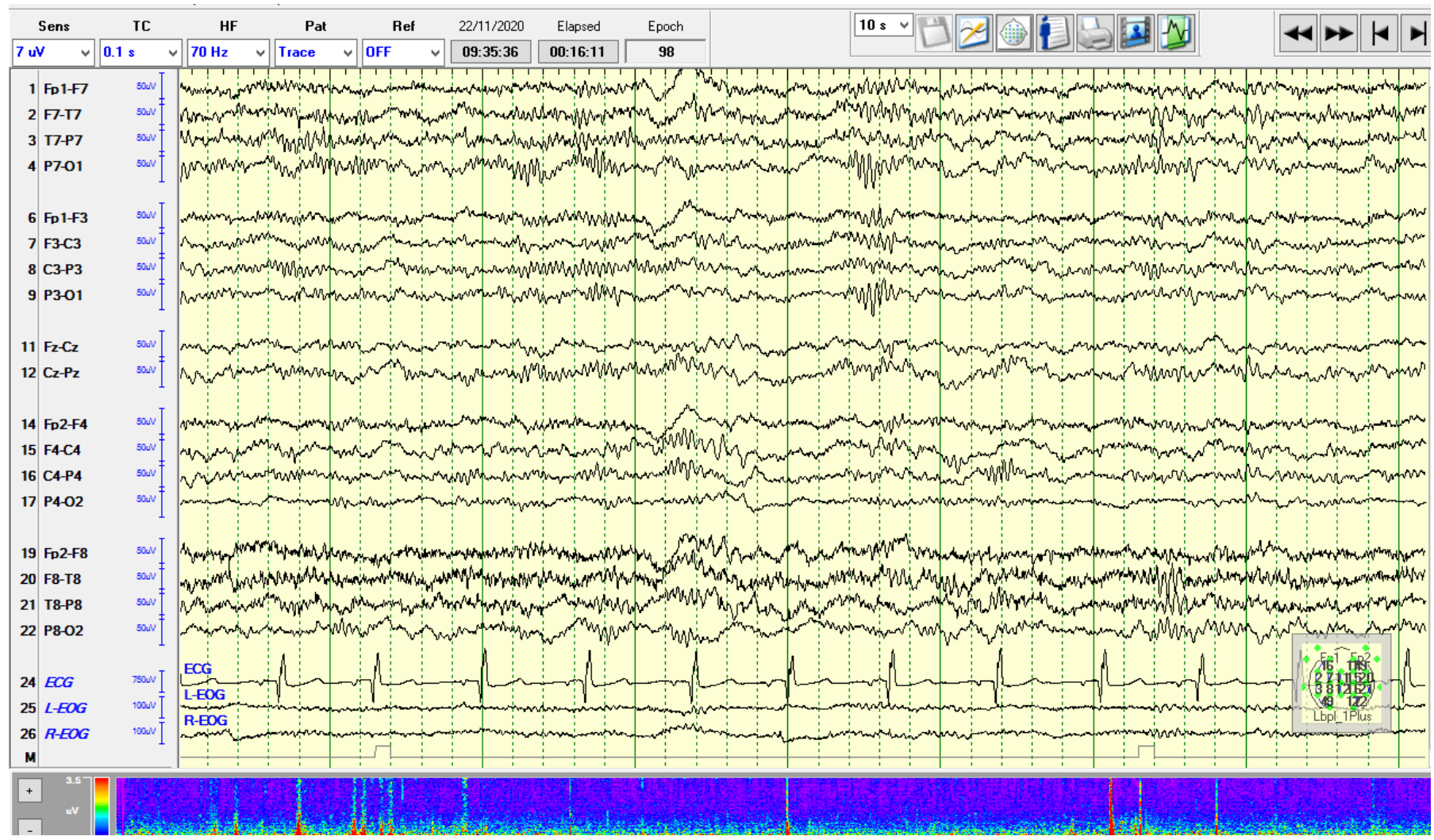

About treatment, 20 different antiepileptic drugs (AEDs) were started in the study done by Danique et al. Valproate and lamotrigine were most commonly prescribed.

Another study by Mignot C 2016 (6) Epilepsy was diagnosed in $16 / 17$ patient. When first seizures were documented between (1-8 years) in form of drop attacks, massive myoclonic jerks, atonic seizures, myoclonic absences or absences. A diagnosis of myoclonic astatic epilepsy (MAE, ie, Doose syndrome) and epilepsy with myoclonic absences (EMAs) was made in three and one patients, respectively. The others were diagnosed with unclassified genetic generalized epilepsy (GGE). None had a diagnosis of Lennox-Gastaut syndrome (LGS).

The epilepsy responded to a single antiepileptic drug (AED), mostly sodium valproate, in seven patients and was pharmacoresistant in nine. The most frequent anomalies reported on EEG traces from 16 patients were ictal or interictal bursts of spikes, spike waves or slow waves that were either generalized $(n=13)$, generalized with a posterior predominance or posterior only $(n=5)$. Paroxysmal anomalies were localized to central regions in six instances. Seizures trigger were recognized in seven patients, including photosensitivity ( $P S, n=5$ ), fixation-off sensitivity (FOS, $n=1)$, PS and FOS $(n=1)$ and chewing $(n=1)$.

The main clinical features of our patient (i.e., intellectual disability and absence epilepsy) are compatible with previous reports on patients with SYNGAP1 mutations. Our case provides further support for efficacy of VPA in patients with SYNGAP1 mutation-related epilepsy.

\section{Reference:}

[1]. Danique R.M. Vlaskamp, MD, Benjamin J. Shaw, MD, Rosemary Burgess, PhD et al . SYNGAP1 encephalopathy, A distinctive generalized developmental and epileptic encephalopathy. Neurology. 2019 Jan 8; 92(2): e96-e107.

[2]. Jeavons PM. Nosological problems of myoclonic epilepsies in childhood and adolescence. Dev Med Child Neurol 1977;19:3-8. [PubMed] [Google Scholar].

[3]. Doose H, Gerken H, Leonhardt R, Völzke E, Völz C. Centrencephalic myoclonic-astatic petit mal: clinical and genetic investigation. Neuropadiatrie 1970;2:59-78. [PubMed] [Google Scholar]. 
[4]. Hamdan FF, Gauthier J, Spiegelman D, et al. . Mutations in SYNGAP1 in autosomal nonsyndromic mental retardation. $\mathrm{N}$ Engl $\mathrm{J}$ Med 2009;360:599-605. [PMC free article] [PubMed] [Google Scholar].

[5]. Celina von Stülpnagel 1, Claudia Funke, SYNGAP1 Mutation in Focal and Generalized Epilepsy: A Literature Overview and A Case Report with Special Aspects of the EEG. Neuropediatrics . 2015 Aug;46(4):287-91. doi: 10.1055/s-0035-1554098. Epub 2015 Jun 25

[6]. Mignot C, von Stülpnagel C, Nava C, et alGenetic and neurodevelopmental spectrum of SYNGAP1associated intellectual disability and epilepsy Journal of Medical Genetics 2016;53:511-522cv 